\title{
Emoções e afetividades: implicações e perspectivas no Ensino de Biologia
}

\author{
Emotions and affectivities: implications and perspectives in Biology \\ Teaching
}

\section{Emociones $y$ afectividades: implicaciones $y$ perspectivas en la Enseñaza de Biología}

Antonia Railene de Souza Rodrigues ${ }^{1}$; Aldair de França-Neto²; Alana Cecília de Menezes Sobreira ${ }^{3}$; Bruno Edson-Chaves ${ }^{4}$

\section{RESUMO}

Aspectos emocionais e afetivos estão diretamente envolvidos com o processo de ensino e aprendizagem. Sendo assim, a pesquisa objetivou investigar a compreensão de professores da Educação Básica da rede pública de ensino de Iguatu-CE sobre como as emoções dos alunos estão envolvidas no processo de aprendizagem discente. Para tanto, entrevistou-se dez professores de Biologia, sendo avaliado o conteúdo de suas respostas. Os docentes informaram que vários fatores interferem na aprendizagem dos discentes, destacando os relacionados as emoções e as relações familiares dos estudantes. Há diferenças emocionais entre alunos de anos diferentes devido ao processo de amadurecimento dos adolescentes, além de fatores como sono e estresse que interferem negativamente na aprendizagem. Ações que trabalhem o emocional dos estudantes e formações continuadas para professores sobre o assunto supracitado podem ser feitas para melhorar o desempenho dos discentes. Para que a aprendizagem dos estudantes se torne cada vez mais efetiva é importante que o professor esteja atento a todos os fatores importantes no processo de ensino e aprendizagem sejam eles curriculares, pedagógicos e/ou emocionais.

Palavras-chave: Sentimentos; Aprendizagem; Relações Interpessoais.

\begin{abstract}
Emotional and affective aspects are directly involved in the teaching and learning process. Therefore, the research sought to investigate the comprehension of Basic Education teachers from the Public Teaching Network of Iguatu city, in the state of Ceara, Brazil, about how students'emotions are involved in their learning process. For this purpose, ten Biology teachers were interviewed and had their answers evaluated. The teachers reported multiple factors interfering with students' learning, highlighting those related to their emotional issues and family relationships. According to the student's grade and age, emotional differences become evident, resulting from the teenage years maturing process. A phenomenon that, along with poor sleep and stress, interferes negatively with learning. What can be done to improve the students' performance is adopting measures to assure them emotional support besides providing continuous training for teachers about the subject
\end{abstract}

\footnotetext{
${ }^{1}$ Licenciada em Ciências Biológicas e Mestranda do Programa Multicêntrico de Pós-graduação em Bioquímica e Biologia Molecular (PMBqBM) da Universidade Federal do Cariri (UFCA), Juazeiro do Norte/CE - Brasil. E-mail: railenerodrigues003@gmail.com

2 Doutor em Fisiologia Humana e Professor assistente no curso de Enfermagem na Faculdades Metropolitanas Unidas (FMU), São Paulo/SP - Brasil. E-mail: aldair.franca@gmail.com

${ }_{3}$ Doutora em Bioquímica e Professora da Universidade Estadual do Ceará, Iguatu/CE - Brasil. E-mail: alana.cecilia@uece.br

${ }^{4}$ Doutorando em Ciências Biológicas (Botânica) pelo programa de pós-graduação em Botânica da Universidade de São Paulo (USP) e Professor da Universidade Estadual do Ceará, Iguatu/CE - Brasil. E-mail: bruno.edson@uece.br
} 
aforementioned. For the students' learning to become increasingly effective, teachers must be aware of all the important factors in both the teaching and learning process, be them curricular, pedagogical, or emotional.

Keywords: Feelings; Learning; Interpersonal Relationships.

\section{RESUMEN}

Aspectos emocionales y afectivos están directamente involucrados con el proceso de enseñanza y aprendizaje. Siendo así, la investigación tuvo como objetivo la comprensión del profesorado de la Educación Básica del sistema público educativo de Iguatu-CE sobre como las emociones de los alumnos están involucradas en el proceso de aprendizaje. Para eso se entrevistó diez profesores de Biología, siendo evaluado el contenido de sus respuestas. Los docentes informaron que varios factores interfieren en el aprendizaje de los alumnos, destacando los relacionados a las emociones y a las relaciones familiares de los estudiantes. Hay diferencias emocionales entre los alumnos de años escolares diferentes debido al proceso de madurez de los adolescentes, allá de los factores como sueño y estrés que interfieren negativamente en el aprendizaje. Acciones que contribuyan para el desarrollo emocional de los estudiantes y formaciones continuas sobre el asunto supracitado pueden ser realizadas para mejorar la evolución de los alumnos. Para que el aprendizaje de los estudiantes se vuelva cada vez más efectiva es importante que el profesor esté atento a todos los factores importantes en el proceso de enseñanza y aprendizaje, sean curriculares, pedagógicos y o emocionales.

Palabras clave: Sentimientos; Aprendizaje; Relaciones Interpersonales.

\section{INTRODUÇÃO}

As emoções são reações natas do ser humano, produtos de atividades cerebrais, como por exemplo a alegria, a raiva, o estresse e até mesmo a dor. Existe um conjunto de emoções primárias que estão presentes no ser humano desde o nascimento e provavelmente estão relacionadas com o instinto de sobrevivência como o medo, a alegria e a raiva; também há aquelas adquiridas ao longo do tempo, entre elas o amor, a tristeza, a paixão, o desespero, a vergonha e a surpresa (AMARAL, 2007).

Essas reações advêm do sistema límbico que é responsável pelo controle emocional do ser humano, como também pela promoção das sensações relacionadas aos processos emotivos (GOMES, 2010). Elas estão fortemente envolvidas com o processo de aprendizagem, uma vez que, experiências que apresentam superior valor emocional são consolidadas mais facilmente pelo ser humano. Assim, conteúdos carregados de emoção serão mais facilmente aprendidos pelos alunos. Quanto mais significados são atribuídos a determinado assunto ou fato, mais facilmente será a capacidade de relembrar (BEZERRA; GUSMÃO; FERMOSELI, 2017).

Uma hipótese culturalmente bem aceita é dizer que as emoções e a afetividade na sala de aula podem favorecer a aprendizagem, como também podem afastar o discente da mesma; o professor, na sua forma de se comportar, gera sentimentos e emoções que podem influenciar a aprendizagem, de modo a afetar a relação do estudante com o conteúdo, com a escola, com o professor e consigo mesmo (TASSONI; SILVA-LEITE, 2011).

Além dos fatores relacionados as emoções, é possível destacar os problemas associados com o estresse e o sono como complicadores da aprendizagem. O estresse pode apresentar inúmeras causas, desde uma ordem psicológica ou física, sendo um processo que ocorre em todos os seres vivos. Já o sono, é indispensável para a regulação do corpo, descanso e recuperação fisiológica do cérebro e ajuda a consolidar o que foi aprendido (MALVA 2007). Contudo, o estresse e problemas como o sono em alunos em sala de aula, pode comprometer o aprendizado dos mesmos (PEREIRA, 2011). 
As emoções e os sentimentos são manifestações da afetividade (FARIAS, MAIA, OLIVEIRA, 2019). Sendo esta última diretamente envolvida com o processo de ensino e aprendizagem, é imprescindível na relação entre alunos e professores. A afetividade está sempre presente na sala de aula, podendo ocorrer de forma positiva ou negativa. Ao se pensar em afetividade na escola é necessária uma reflexão sobre as diversas situações que os discentes e os docentes se encontram (ROSA; CASTRO, 2017). Afeto e cognição são elementos inseparáveis, fazendo parte de qualquer atividade, sendo que o primeiro se caracteriza como um combustível necessário para que a estrutura cognitiva funcione na sua completude (FARIAS; MAIA; OLIVEIRA, 2019).

Para que haja aprendizagem é importante uma relação de afeto entre professor e aluno. Essa afetividade precisa ser estimulada e isso pode ser feito através da convivência entre os pares. Esse fator possibilita aproximar o estudante do professor, consequentemente o aproxima dos conteúdos estudados e com isso pode estimular a aprendizagem. Quando pessoas se sentem seguras aprendem com maior facilidade, e a afetividade proporciona isso (FARIAS; MAIA; OLIVEIRA, 2019).

Considerando a importância dos processos emotivos/afetivos na sala de aula o objetivo desse artigo foi investigar a compreensão de professores da Educação Básica da rede pública de ensino do município de Iguatu-Ceará sobre como as emoções dos alunos estão envolvidas no processo de aprendizagem discente.

\section{METODOLOGIA}

\subsection{Tipo de pesquisa}

Essa pesquisa apresenta natureza qualitativa que busca compreender e ainda fazer uma interpretação acerca dos fenômenos que se relacionam a uma dada população, a qual está inserida, em um determinado contexto social (BORTONI-RICARDO, 2008). Também apresenta caráter exploratório já que busca investigar sobre um determinado assunto e assim, adquirir maior familiaridade com o tema. As pesquisas exploratórias são importantes quando não se sabe o suficiente sobre um fenômeno (GRAY, 2012; GIL, 2010), no caso desse artigo, o quanto as questões emocionais e afetivas interferem na aprendizagem dos alunos, na percepção dos professores. A pesquisa desenvolvida tem uma abordagem descritiva em que busca descrever as características de uma determinada população e pode ser elaborada com a finalidade de buscar possíveis relações entre variáveis (GIL, 2010).

\subsection{Local e sujeitos da pesquisa}

A pesquisa foi realizada no município de Iguatu, localizado na região Centro-Sul do estado do Ceará, a 365 quilômetros da capital Fortaleza. Os sujeitos da pesquisa foram dez professores de Biologia das escolas estaduais de Ensino Médio da sede do município. Ao todo, participaram 76,92\% dos docentes formados em Biologia e atuantes na rede estadual de ensino do município de Iguatu. O foco nestes professores ocorreu devido aos participantes estarem envolvidos nas pesquisas sobre ensino e aprendizagem em Biologia realizadas pela equipe executora deste trabalho. Como forma de manter o anonimato dos sujeitos, estes foram organizados em letras de A à J e a participação deles na pesquisa, se deu de forma voluntária. 


\subsection{Coleta de dados}

Como instrumento de coleta de dados foi utilizada entrevista semiestruturada, método mais comum em pesquisas qualitativas. Para tanto, foi elaborado um roteiro de perguntas que envolviam: se fatores emocionais podem interferir na aprendizagem; se há diferenças emocionais entre alunos de diferentes anos que podem interferir no processo de aprendizagem; como o estresse e/ou problemas com o sono podem interferir no aprendizado do estudante; que fatores mais interferem na aprendizagem e o que pode ser feito na escola para melhorar o desempenho dos alunos. Assim, com o consentimento dos professores, foi utilizado recurso eletrônico para gravar a entrevista que, mais adiante, foi transcrita e analisada.

\subsection{Aspectos éticos e legais da pesquisa}

A coleta dos dados se deu com o consentimento dos professores, respeitando os aspectos éticos e legais da pesquisa em seres humanos que garante respeito, proteção e dignidade aos sujeitos pesquisados (BRASIL, 2012). Dessa forma, no ato da entrevista, para cada entrevistado, foi entregue o Termo de Consentimento Livre e Esclarecido - TCLE garantindo escolha para participar da pesquisa de forma voluntária, o sigilo e a fidelidade dos dados.

\subsection{Tratamento dos dados}

As respostas dadas pelos sujeitos da pesquisa durante a entrevista foram transcritas e analisadas de acordo com a metodologia de Bardin (2011), ou seja, diferentes categorias foram criadas de acordo com as respostas dos sujeitos. Frequentemente as falas dos docentes foram incluídas em mais de uma categoria e por isso, os dados da análise são apresentados em números absolutos e eventualmente o somatório total pode ser superior ao número de sujeitos da pesquisa.

\section{RESULTADOS E DISCUSSÃO}

Todos os professores dessa pesquisa são formados em Biologia, possuem mais de 5 anos de experiência na docência, já participaram de formações continuadas e a maioria deles possui Especialização. Contudo, das especializações realizadas pelos sujeitos da pesquisa, apenas três possuem caráter pedagógico.

De acordo com a concepção dos professores, os fatores emocionais na sala de aula podem interferir na aprendizagem dos alunos, seja de forma positiva, negativa ou de ambas as formas. Nesse sentido, as falas dos sujeitos distribuíram-se nas seguintes categorias:

1. Problemas emocionais interferem negativamente no processo de aprendizagem (5 Professores);

2. Afetividade e a relação professor-aluno (2);

3. Aspectos pessoais, fora do convívio escolar, interferem no aprendizado (5);

4. Disciplinas que trabalham o lado emocional do aluno contribuem para a aprendizagem do aluno (1). 
As categorias 1 (problemas emocionais interferem negativamente no processo de aprendizagem) e 3 (aspectos pessoais, fora do convívio escolar, interferem no aprendizado) foram bastante evidenciadas nas falas dos sujeitos, neste sentido é possível destacar o discurso do professor C:

Eu acho que totalmente, um aluno quando não tá bem focado, por conta de alguma coisa que aconteceu em casa, de manhã cedo, às vezes tem uma briga em casa... ele não vai chegar e focar, pensar na aula, ele vai tá com o pensamento na casa dele no que aconteceu, que deixou de acontecer, questão de sentimentos, principalmente na adolescência, em que os hormônios estão a flor da pele (Professor C, categorias 1 e 3).

Nessa configuração do pensamento, é importante, no ambiente familiar, que as crianças e os adolescentes desenvolvam as funções emocionais bem estruturadas. Se a família desenvolve esse papel, só tende a contribuir para o desenvolvimento dos filhos, caso contrário, se esse ambiente não apresentar as condições de desenvolvimento adequadas, pode comprometer a aprendizagem dos alunos. A participação da família na escola e a percepção da escola sobre as demandas familiares dos alunos favorece o desenvolvimento do aluno em diversos setores incluindo o afetivo e o intelectual (COSTA; SILVA; SILVA-SOUZA, 2019). Os pressupostos Wallonianos apontam a importância do meio social em geral em que o aluno está inserido para possibilitar o seu desenvolvimento, sendo a família e a escola os principais representantes, mas não apenas estes, mas tudo aquilo que o cerca (SILVA, 2017).

Tavares (2014, p. 39) cita que "o desenvolvimento afetivo, o desenvolvimento cognitivo e o desenvolvimento social não ocorrem de forma ordenada ou sequencial, e sim de forma concomitante, paralela e simultânea". Os processos afetivos, sentimentos e emoções, marcam substancialmente a relação entre aluno e professor, podendo afastá-lo ou aproximá-lo do conhecimento (TASSONI; SILVA-LEITE, 2011). Ter reações emotivas é interessante, pois nos deixa vigilantes e atentos. Por outro lado, as emoções podem ser prejudiciais, desenvolvendo a ansiedade e o estresse em efeito prolongado, interferindo de forma negativa, sendo sempre necessário considerá-las no processo educacional (COSENZA; GUERRA, 2011).

A escola também tem o papel de trabalhar os fatores afetivos com os alunos, sendo necessária uma discussão sobre esse assunto no ambiente escolar. Há várias formas dos professores ajudarem os alunos nessa perspectiva, tanto em intervenções sobre o tema, quanto na organização de seus conteúdos (TASSONI; SILVA-LEITE, 2011). Para Wallon, a escola é uma instituição fundamental que possibilitaria ao sujeito aprender princípios da cultura científica, que valoriza as relações entre professor e aluno e o desenvolvimento das potencialidades destes. Este conduz sua teoria no desenvolvimento da pessoa completa, aproximando a psicologia e a pedagogia, de modo a valorizar a formação de educadores e promover ambientes educativos adequados para o crescimento do educando em todos os seus aspectos (SILVA, 2017).

Nesse contexto, é importante destacar o discurso do professor G que se encaixa na categoria 2, afetividade e a relação professor-aluno:

Nós somos emoções, eu jamais vou conseguir dar uma aula bem se eu não tiver bem emocionalmente, então do mesmo jeito é o aluno, se na sala de aula ele tá bem emocionalmente, e até mesmo durante a aula o professor... É o que a gente chama de afetividade, de trazer o aluno pra perto, pra que a partir daí ele tenha mais interesse na aula, eu acho que isso influencia totalmente. $O$ fator emocional influencia totalmente na aprendizagem (Professor G, categoria 2). 
Tassoni e Silva-Leite (2000) citam que a interação entre alunos e professores melhora a autoestima e a autoconfiança, que interferem diretamente para a aprendizagem. Revela ainda outros sentimentos positivos, entre eles: simpatia, compreensão, respeito, aceitação e valorização. Essas experiências possibilitam a afetividade na relação entre os sujeitos, que além de possibilitar o conhecimento, favorece autonomia e confiança dos alunos.

A afetividade simbolizaria práticas de respeito, cuidado e colaboração mútuos o que, por consequência, possibilitaria estabelecer ou reforçar laços de amizade e carinho entre os indivíduos envolvidos. Defendemos, assim, uma sensibilização docente no que tange ao reconhecimento da influência positiva do afeto em contextos educacionais. A reciprocidade entre afetividade e cognição qualifica as relações entre professor e estudante resultando no bem-estar de ambos. Logo, essa associação contribui para a aprendizagem discente e para o sucesso profissional do educador, aumentando possivelmente sua motivação e autoestima (OLIVEIRA-HAHN; FERRARO, 2018, p. 1334).

Brait e colaboradores (2010) acrescentam que essa relação no processo de ensino e aprendizagem depende do ambiente que o educador estabelece e da relação de empatia entre ele e o educando. 0 professor deve criar pontes entre o conhecimento e seus alunos e educar desenvolvendo o lado positivo para a formação cidadã. Os pressupostos de Durkheim (2011) sugerem que o professor se submeta a profundas reflexões pedagógicas, como forma de conhecer melhor o seu aluno, bem como busque meios para favorecer o seu desenvolvimento.

Em relação às emoções na sala de aula, foi questionado aos educadores se eles percebem diferenças emocionais entre alunos de anos diferentes que possam influenciar na aprendizagem. Os professores consideraram que há diferenças nas emoções entre alunos de primeiro, segundo e terceiro ano, sendo que a maioria diz ser essa diferença relacionada ao desenvolvimento da maturidade. Desse modo, as falas estão divididas nas seguintes categorias:

1. Alunos ingressantes são mais imaturos e inseguros e no decorrer do tempo vão adquirindo maturidade e segurança (7 professores);

a. Desenvolvimento da maturidade relacionada a cognição (3);

b. Desenvolvimento da maturidade relacionada a fatores psicológicos (4);

2. Relativo a base educacional que o aluno adquiriu nos anos anteriores (1);

3. Cada ano apresenta diferença no emocional dos alunos de acordo com o que eles vão vivenciando (3);

A categoria mais representativa foi a 1 , em que os professores acreditam que os alunos são mais imaturos nos anos iniciais do Ensino Médio, e com o passar do tempo eles vão se tornando mais maduros. Contudo, é possível destacar que as justificativas em relação ao processo de amadurecimento dos alunos ao longo dos anos podem ser divididas em duas: a maturidade em relação aos fatores psicológicos e/ou maturidade em relação ao conhecimento dos conteúdos como pode ser evidenciado nas transcrições abaixo:

Sim, a gente sabe que o estudante ele vai passando pelo processo de aprendizagem e educação, é por isso que ele não tá na série inicial e ele pula, exatamente por causa do amadurecimento do cérebro, a cognição desse menino, um menino de 5 anos é diferente de um de 10 anos. É por isso que hoje já se coloca na escola o estudante 
na idade certa, o ensino fundamental já vê isso, exatamente por conta da aprendizagem (Professor F, categorias 1a).

Sim, o aluno de terceiro ano, ele já se sente mais importante, é um aluno que você fala com ele e por estar no terceiro ano, ele acha que é a última bolacha do pacote. Ele acha que tá terminando, que vai fazer ENEM, vai entrar numa universidade, então ele já está com aquela expectativa tão bem estabelecida, que ele é realmente extremamente confiante. Já o aluno de primeiro ano, não. Ele está chegando, ele é inseguro [...] (Professor A, categorias 1b).

A maturidade apresenta vários aspectos, entre eles o intelectual, o físico e o social (CORDEIRO, 2011). De acordo com os dados analisados nessa pesquisa, a maturidade intelectual e social está mais associada às categorias 1 e 3, respectivamente.

Sobre maturidade intelectual, Cordeiro (2011) afirma que a aprendizagem não está relacionada apenas com o passar da idade, mas também aos fatores que cercam a vida do sujeito como, por exemplo, a maturidade emocional. O ambiente em que o aluno está inserido e a educação desempenham papéis importantes no tocante ao desenvolvimento da maturidade cognitiva.

No que se refere à maturidade social e aqui inclui os fatores emocionais, Cosenza e Guerra (2011) argumentam que a expressão das emoções na sala de aula deve ser respeitada, como também precisa ser desenvolvida e isso contribui para o fortalecimento da aprendizagem além de orientar os alunos a viver em sociedade buscando a realização pessoal.

Um dos professores destacou que a base emocional dos alunos é considerada de acordo com a educação inicial adquirida pelo aluno nos anos de estudos anteriores, como também na relação com a família. Para Cosenza e Guerra (2011) uma das possíveis razões para as diferentes reações emocionais apresentadas pelos alunos na escola muitas vezes é motivada por problemas externos com por exemplo, as questões familiares.

Percebe-se a partir desses primeiros questionamentos que processos afetivos precisam ser desenvolvidos no ambiente escolar, contudo este não é o único influenciador no desenvolvimento do aluno, várias questões como família, sociedade, fase de desenvolvimento em que o discente se encontra, bem com a relação com professores e colegas fazem parte desse processo. Os professores até o momento enfatizam muito o fator família no diálogo, apontando como a família tem um papel importante na vida do estudante, já que esta é principal base e referência do discente.

Sobre como os problemas relacionados ao estresse e a sonolência, observada nos alunos podem interferir no aprendizado, percebeu-se pelas respostas dos sujeitos da pesquisa que esses, são fatores intrinsecamente associados ao rendimento e ao aprendizado do aluno. Para discutir esse questionamento, as seguintes categorias foram criadas:

1. Falta de descanso para o cérebro / sono noturno insuficiente (9 professores);

2. Sono vespertino (fisiológico) (1);

3. Sono ligado ao estresse (1);

4. Estresse devido a problemas externos (5);

5. Aspectos ligados a ansiedade (1). 
Em relação a categoria 1 (falta de descanso para o cérebro / sono noturno insuficiente), é possível destacar os discursos dos professores A e I sobre a importância do sono noturno para o cérebro:

Eu acho que totalmente, nós precisamos dormir para descansar o nosso cérebro, e hoje a juventude tá vivendo a noite. Você veja que a maioria das pessoas hoje se liga na internet às 9 da noite, vai desligar as 3:00, 4:00 da manhã, quando é 7:00 da manhã já tem que tá trabalhando ou na escola, e aí o que é que o cérebro descansou, o que ele processou? Nada. $E$ aí isso vai se acumulando e esse efeito cumulativo vai gerando no cérebro um estresse de tal maneira que eles não percebem (Professor $A$, categoria 1).

[...] Se o aluno tem uma noite mal dormida pelos problemas da vida, aí se ele vem para a escola com sono ele tá o corpo presente aqui, mas o raciocínio dele não tá na sala (Professor I, trecho que corresponde a categoria 1).

O sono é um mecanismo importantíssimo para a homeostase do organismo, visto que mantém o cumprimento correto de funções fisiológicas e psicológicas. Um sono de boa qualidade é imprescindível, pois atua na manutenção das funções cognitivas, consolidação da memória e da aprendizagem, importantes para o desempenho escolar do adolescente (COUTO; SARDINHA; AQUINO-LEMOS, 2018).

A aprendizagem ocorre através da consolidação da memória, sendo as etapas do sono essenciais nessa tarefa. Durante essas etapas, mudanças neuronais são produzidas com a finalidade de manter ou fortalecer as novas sinapses e circuitos neuronais que estão relacionados à conversão de aprendizado e a memória de curta duração em memória de longo prazo (VALE; VALE; REIMÃO, 2009). A privação do sono pode ocasionar danos na aprendizagem e por conta disso, os alunos precisariam de mais cuidados e atenção (COUTO; SARDINHA; AQUINO-LEMOS, 2018).

Outra categoria bastante expressada pelos sujeitos da pesquisa foi a categoria 4 (estresse devido a problemas externos). Em relação a esta cabe destacar as seguintes transcrições:

Quando o aluno vem de bem consigo mesmo é mais fácil de você trabalhar, ele fica mais receptivo, ele acaba desenvolvendo as atividades melhor, ele recebe com mais gosto. Quando ele já vem estressado as vezes nós mesmos professores somos o saco de pancadas, você vai falar com ele: ele já vem assim, já vem com... E acaba refletindo na gente também, então o estresse atrapalha com certeza o desempenho deles em sala de aula $[\ldots]$ (Professor B, trecho relacionado a categoria 4).

Uma vez que querendo ou não no dia a dia o estresse que eles já vêm de casa, muitas vezes que eles desenvolvem o não querer e atinge principalmente o processo de aprendizagem deles (professor J, categoria 4).

Estresse é entendido como um estado de tensão resultado de situações que ocorrem ao longo da vida em que não conseguimos lidar. Essas alterações impactam a vida das pessoas causando alterações em seu desenvolvimento, principalmente no ambiente escolar (BUSNELLO; SCHAEFER; KRISTENSEN, 2009). Nesse sentido, deter conhecimentos sobre o efeito do estresse, abordado do ponto de vista neurobiológico pode enriquecer a prática educativa de modo a permitir ao professor lidar melhor com a situação, uma vez que possuirá conhecimentos sobre o assunto, podendo ainda ser reflexivo sobre sua prática de ensino (MELO-JÚNIOR et al., 2014).

De fato, fatores como sono e estresse dificultam o processo de aprendizagem pelo estudante, assim, a família, a escola e o estudante precisam possuir o papel de minimizar esses eventos. Contudo, em alguns casos esses fatores são complicados, há alunos com diversas realidades sociais, algumas melhores, outras mais complexas e difícil de lidar, sendo importante a empatia por parte dos 
envolvidos em conhecer e reconhecer esse aluno, como parte de uma sociedade plural, de diversas realidades.

Os sujeitos da pesquisa foram perguntados sobre os fatores que possivelmente interferem na aprendizagem dos alunos e as respostas apresentadas foram alocadas nas seguintes categorias:

1. Falta de regras (1 Professor);

2. Imaturidade (1);

3. Falta de perspectiva (1);

4. Fatores emocionais (6);

5. Ensino fundamental mal feito (1);

6. Questões familiares (4);

7. Uso de aparelhos celulares (1);

8. Métodos de ensino inadequados (2);

9. Ansiedade (1);

10. Baixa autoestima (1);

11. Relação professor x aluno (1).

As categorias criadas para agrupar as respostas dos sujeitos, evidenciam que são vários os fatores que podem comprometer o processo de aprendizagem dos alunos. Dentre eles, merecem destaque os fatores relacionados as questões emocionais e os fatores relacionados as questões familiares como pode ser lido nas transcrições abaixo:

Eu acho que a questão familiar mesmo, a estrutura, os problemas, que infelizmente o adolescente não tem maturidade, [...] o adolescente de hoje se apega muito, a muitos eventos externos [...] eu acho que vão ampliando essas emoções, eles não conseguem lidar bem [...] (Professor $\mathrm{E}$, categorias 4 e 6 ).

Eu acredito que são fatores externos, é... Quando eu falo fatores externos eu falo fatores da família [...] alunos que vem de famílias desestruturadas e a gente tem uma grande dificuldade de estruturar aquele aluno, ele não tem uma formação cidadã, ele não tem formação social e a gente precisa, primeiro, trabalhar isso [...], eles precisam ter essa formação pessoal, então fator externo família, interfere muito na aprendizagem do aluno (Professor $\mathrm{H}$, categorias 4 e 6 ).

Os problemas emocionais foram descritos como aspectos que interferem na aprendizagem por Mazer, Bello e Bazon (2009). Já Bonatto et al. (2012) destacam que entre os fatores que mais interferem na aprendizagem dos alunos estão a relação destes com os pais e as questões familiares de modo geral. Pode haver uma ligação ainda desses aspectos emocionais associada à família; "a origem das reações emocionais na escola pode estar relacionada com problemas externos, originados, por exemplo, no contexto familiar ou social" (COSENZA; GUERRA, 2011 p.84).

Com relação à categoria 7, uso de aparelhos celulares, destaca-se a fala do professor H: 
Há dispersão, com relação, por exemplo, ao uso do celular, porque é polêmico essa questão, tem escola que proíbe, outras não, então o celular atrapalha [...] (Professor $\mathrm{H}$, trecho da fala relacionada a categoria 7).

O uso de aparelhos celulares no contexto educacional é um assunto que divide muitas opiniões. Por um lado, a utilização dessa mídia pode ser uma das causas de distrações na sala de aula, por outro lado é considerada como um recurso didático (BATISTA; BARCELOS, 2013). De acordo com Bento e Cavalcante (2013) o uso de aparelhos celulares pode ser utilizado como recurso pedagógico, servindo além de um instrumento de entretenimento dos alunos; contudo, é necessário planejamento e organização para que esse recurso seja utilizado de modo a favorecer a aprendizagem.

De fato, esses aparelhos possuem empregos de uso tanto de forma positiva quanto negativa, o importante, caso seja permitido o aparelho na escola, é saber usufruir desse recurso a favor da aprendizagem, e para isso se faz necessário disciplina e comprometimento de alunos e professores.

Em menor proporção, os professores citaram pontos como ansiedade e a baixa autoestima do aluno como fatores que podem interferir na aprendizagem. Sobre ansiedade, Lopes e Gonçalves (2020) apontam que esta pode ser considerada como uma emoção normal do ser humano, contudo, em demasia pode influenciar negativamente, trazendo malefícios para o desenvolvimento do aluno. Uma pesquisa realizada por Mendes et al. (2017) com professores e alunos de diversas faixas etárias mostrou que tanto os pais, quanto professores e colegas contribuem significativamente para a formação da autoestima do aluno.

Muitas ações podem ser feitas para melhorar o desempenho dos alunos na escola. No que se refere a isso, possíveis soluções foram destacadas pelos professores e são apresentadas nas categorias abaixo:

1. Através de ações que trabalhem o emocional dos alunos (6);

2. Mudança do horário de início das aulas (1);

3. Ambiente escolar tranquilo (1);

4. Conhecer bem o aluno (2);

5. Ter formações continuadas sobre aspectos da educação (3);

6. Trabalhar a afetividade (1);

7. Redução do número de alunos na sala de aula (1).

No que diz respeito a categoria 1, ações que trabalhem o emocional dos alunos, cabe destacar a transcrição do professor A:

A escola poderia talvez ter psicólogos para fazer o papel deles, já que o professor assume todos os papeis de forma totalmente desordenada, porque nós não somos psicólogos e nem psiquiatras, e estamos fazendo o papel de... Desse papel. Eu acho que o começo é na verdade, as pessoas tentarem estabelecer famílias saudáveis acho que seria o principal papel [...] (Professor A, categoria 1).

Martínez (2010, p. 42) aponta que psicólogos podem atuar na escola desempenhando diversas atividades a fim de contribuir para a aprendizagem, contudo não deve ser reduzido ao trabalho em relação a "diagnóstico, atendimento, orientação e intervenção em relação aos problemas emocionais 
de aprendizagem e de comportamento". O psicólogo também tem o papel de contribuir nas relações entre alunos e professores, a fim de contribuir para o desenvolvimento afetivo e emocional (SAMPAIO et al., 2018).

Na fala do entrevistado A são apresentados aspectos ligados a família para melhorar o desempenho dos alunos. Desse modo a família, escola e aluno são fundamentais para a melhoria da aprendizagem dos alunos, sendo necessária a relação entre os contextos família e escola para o desenvolvimento do estudante (DESSEN; COSTA-POLONIA, 2007).

No que tange a categoria 6 , trabalhar a afetividade, os professores $\mathrm{F}$ e I disseram que:

A primeira coisa que acho que se tem que mudar na escola é o professor [...] então se não tiver formação continuada para esse professor, ele vai continuar usando as mesmas metodologias arcaicas, de dez, quinze, vinte anos, e acredita-se muito que a formação continuada, ela pode mudar esse paradigma, desse ensino tradicional tão impregnado nos professores [...] (Professor F, categoria 6).

Eu acredito que a escola poderia fazer uma formação com os próprios professores e a partir da didática utilizar essas técnicas que a neurociência tem e aprimorar dentro da sala de aula (Professor I, categoria 6).

De acordo com Medeiros, Rodrigues e Cavalcante (2017) é importante o incentivo à formação continuada de educadores, pois através disso ocorre a melhoria do ensino uma vez que contribui para a prática e valorização da profissão docente, sendo indispensável para garantir novos conhecimentos e atualizações às modernas demandas educacionais (SANTOS; CARVALHO; DOMINGUES, 2019).

Os professores destacaram que conhecer bem o aluno (categoria 4) e a redução do número de alunos na sala de aula (categoria 7), como relevantes às ações que podem ser feitas para melhorar a realidade da aprendizagem. No tocante a categoria 4 é importante que a escola seja um lugar calmo, disposto a fortalecer um vínculo com o aluno, e que este se sinta à vontade nesse ambiente e queira estar nele, pois, talvez assim, ele se envolva cada vez mais com as questões pedagógicas e dessa forma, favoreça o seu aprendizado. Em relação à categoria 7, estudos recentes apontam que existe uma relação negativa entre o número de alunos e o desempenho nas aulas/disciplinas, quanto maior o número de estudantes, menor é o desempenho em sala de aula (PEIXOTO; AGUIAR, 2018; ANNEGUES; PORTO-JÚNIOR; FIGUEIREDO, 2020).

Na escola pública, são comuns turmas superlotadas, isso pode ser um problema, visto que a aprendizagem é construída no coletivo, mas também na individualidade com cada aluno. Um professor compromissado com a sua atividade de despertar o interesse e a aprendizagem de todos os alunos fica sobrecarregado, podendo interferir negativamente no seu papel de educador, como também na relação com os alunos, interferindo também nas relações interpessoais. Dessa forma, tanto o ensino por parte do professor quanto a aprendizagem dos alunos pode ser comprometida.

Ao educador são atribuídas inúmeras responsabilidades, tais como formação para a cidadania, conhecimento e domínio de tecnologias e métodos de ensino, papel de estimulador, orientador, mediador, mentor, e não apenas de facilitador da aprendizagem de conteúdos. Dessa forma, para que ele consiga exercer o seu papel é preciso que o todas as esferas responsáveis: Estado, Escola e Sociedade propiciem condições mínimas para isso. Mas isso nem sempre ocorre, muitas vezes, faltam recursos, apoio e valorização desses profissionais restando ao professor apenas sua força de vontade e desejo de mudança, o que é muito desanimador. 
Em síntese, esse eixo da pesquisa destaca questões emocionais e afetivas no ambiente escolar que podem interferir na aprendizagem dos alunos, seja de forma positiva ou negativa. Entre os fatores envolvidos na emoção do estudante destaca-se a maturidade, a família, a escola e a sociedade de modo geral. É importante considerar, essas questões no ambiente escolar, pois acredita-se que quando tais assuntos são bem trabalhados em sala de aula a aprendizagem irá ocorrer de forma mais fluida e significativa.

As ideias de Durkhein (2011) propõem que a Educação é essencialmente social. É necessário que esta proporcione comunhão de ideias e sentimentos entre os sujeitos, comunhão essa essencial à sociedade. Wallon (1975) aponta que a o desenvolvimento da personalidade do indivíduo não é influenciada apenas pela herança biológica, mas também pelas interações do indivíduo com a sociedade.

Isso indica que não pode haver educação sem envolvimento entre os pares, ou seja, não é possível uma aprendizagem meramente racional, sem levar em consideração os processos afetivos; alunos, professores e sociedade em geral devem se relacionar para que o ensino e a aprendizagem ocorram. Essa interação é carregada de sentimentos e emoções que não podem ser desvinculadas dos sujeitos. Na verdade, é preciso considerá-la em qualquer âmbito, pois é intrínseco do ser.

\section{CONSIDERAÇÕES FINAIS}

O presente trabalho ressalta que os fatores emocionais e afetivos interferem na aprendizagem dos alunos devendo ser levados em consideração no processo de ensino e aprendizagem. É preciso estar atento a essas questões, pois em um ambiente bem estruturado, que apresenta incentivo a expressão emocional/afetiva, a aprendizagem pode ser potencializada, contudo, o oposto também acontece.

O professor tem contato com o seu aluno quase que diariamente, desse modo é desenvolvido um processo afetivo, mas é importante que sejam afetos positivos. Destaca-se ainda nesta pesquisa que os alunos também manifestam em sala de aula, a carga emocional de convívio diário com a família e com a sociedade em geral, por isso é relevante trabalhar não apenas a aprendizagem em si dos alunos, mas o seu lado emocional, para que isso não prejudique a aprendizagem deles.

Por fim, são muitas as questões que influenciam ou interferem na aprendizagem dos alunos, os processos afetivos/emotivos são apenas um em todo o contexto educativo, mas não menos importante do que os demais. É preciso estudo e reflexão sobre esse tema, bem como sobre o papel de cada sujeito, no processo educativo, já que alunos e professores não são os únicos protagonistas, como foi evidenciado nesta pesquisa. Assim, mais estudos precisam ser conduzidos com estudantes, para evidenciar quais sentimentos e emoções, sobre os diversos aspectos da vida, podem interferir no seu pleno desenvolvimento.

\section{REFERÊNCIAS}

AMARAL, V. L. Psicologia da educação. Natal, RN: EDUFRN, 2007.

ANNEGUES, A. C.; PORTO-JÚNIOR, S.; FIGUEIREDO, E. Tamanho da Turma e Desempenho Acadêmico dos Universitários: evidência para a UFPB. Estudos Econômicos (São Paulo), v. 50, n. 1, p. 99-124, 2020. Disponível em: https://www.scielo.br/pdf/ee/v50n1/0101-4161-ee-50-010099.pdf. Acesso em: 17 abr. 2021. 
BARDIN, L. Análise de conteúdo. Lisboa: Edições, v. 70, 2011.

BATISTA, S. C. F.; BARCELOS, G. T. Análise do uso do celular no contexto educacional. RENOTE, v. 11, n. 1, p. 1-10, 2013. Disponível em: https://seer.ufrgs.br/renote/article/view/41696/26448. Acesso em: 16 abr. 2020.

BENTO, M. C. M.; CAVALCANTE, R. S. Tecnologias Móveis em Educação: o uso do celular na sala de aula. Educação, Cultura e Comunicação, v. 4, n. 7, 2013.

BEZERRA, M. G. C. E; GUSMÃO J. E. L.S; FERMOSELI, A. F. O. A importância da emoção no processo de consolidação da memória e da aprendizagem. Caderno de Graduação-Ciências Biológicas e da Saúde Unit, v. 4, n. 2, p. 57, 2017.

BONATTO, A.; BARROS, C. R.; GEMELI, R. A. LOPES, T. B. FRISON, M. D. Interdisciplinaridade no ambiente escolar. In: SEMINÁRIO DE PESQUISA EM EDUCAÇÃO DA REGIÃO SUL, 9, 2012, Caxias do Sul, RS. Anais... Caxias do Sul, RS, 2012. Disponível em:

http://www.ucs.br/etc/conferencias/index.php/anpedsul/9anpedsul/paper/viewFile/2414/501.

Acesso em: 16 abr. 2021.

BORTONI-RICARDO, S. M. O professor pesquisador: introdução à pesquisa qualitativa. São Paulo: Parábola Editorial, 2008.

BRAIT, L. F. R. MACEDO, M. F.; SILVA, F. B. SILVA, M. R.; SOUZA, A. L. R. A relação Professor/Aluno no processo de ensino e aprendizagem. Itinerarius Reflectionis, v. 6, n. 1, p. 115, 2010. Disponível em: https://www.revistas.ufg.br/rir/article/view/40868/pdf. Acesso em: 16 abr. 2021.

BUSNELLO, F. B.; SCHAEFER, L. S.; KRISTENSEN, C. H. Eventos estressores e estratégias de coping em adolescentes: implicações na aprendizagem. Psicologia Escolar e Educacional, v. 13, n. 2, p. 315-323, 2009. Disponível em: https://www.scielo.br/pdf/pee/v13n2/v13n2a14.pdf. Acesso em: 17 abr. 2021.

BRASIL. RESOLUÇÃO No 466, DE 12 DE DEZEMBRO DE 2012. 2012. Disponível em: http://bvsms.saude.gov.br/bvs/saudelegis/cns/2013/res0466_12_12_2012.html. Acesso em: 03 fev. 2019.

CORDEIRO, M. S. A psicologia desportiva para pré-púberes de 10 a 12 anos. 2011. $12 f$. Artigo (Especialização em Ciência do Treinamento Desportivo) Departamento de Educação Física, Universidade Federal do Paraná, Curitiba, 2011.

COSENZA, R. M; GUERRA, L. B. Neurociência e educação: como cérebro aprende. Porto Alegre: Artmed, 2011.

COSTA, M. A. A.; SILVA, F. M. C.; SILVA-SOUZA, D. Parceria entre escola e família na formação integral da criança. Práticas Educativas, Memórias e Oralidades-Rev. Pemo, v. 1, n. 1, 2019. Disponível em: https://revistas.uece.br/index.php/revpemo/article/view/3476/3127. Acesso em: 17 abr. 2021.

COUTO, C.; SARDINHA, L. S.; AQUINO-LEMOS, V. Relações entre sono e aprendizagem em adolescentes. Diálogos Interdisciplinares, v. 7, n. 4, p. 29-33, 2018.

DESSEN, M. A.; COSTA-POLONIA, A. A família e a escola como contextos de desenvolvimento humano. Paidéia, v. 17, n. 36, p. 21-32, 2007. Disponível em: https://www.scielo.br/pdf/paideia/v17n36/v17n36a03.pdf. Acesso em: 17 abr. 2021. 
DURKHEIM, É. Educação e sociologia. Tradução de e Stephania Matousek. - Petrópolis, RJ: Vozes, 2011 - (coleção Textos Fundantes de Educação).

FARIAS, Á. L. P.; MAIA, D. F.; OLIVEIRA, M. A. T. Lúdico e a afetividade no processo ensino aprendizagem. Cenas Educacionais, v. 2, n. 2, p. 25-41, 2019. Disponível em:

https://revistas.uneb.br/index.php/cenaseducacionais/article/view/8019/5207. Acesso em: 17 abr. 2021.

GIL, A. C. Como elaborar projetos de pesquisa. 5. Ed. São Paulo: Atlas, 2010.

GOMES, J. E. A relação entre afeto e aprendizagem: A partir do sentir e do pensar. ACTA

Brasileira do Movimento Humano, v. 1, n. 1, p.1-10, 2010. Disponível em:

http://www.periodicos.ulbra.br/index.php/actabrasileira/article/view/3060/2250. Acesso em: 17 abr. 2021.

GRAY, D. E. Pesquisa no mundo real. 2. Ed. - Porto Alegre: Penso, 2012.

LOPES, A. C. C.; GONÇALVES, E. G. A. A influência dos transtornos de ansiedade no processo de ensino-aprendizagem. Revista Científica da FEPI-Revista Científic@ Universitas, v. 7, n. 3, 2020. Disponível em: http://revista.fepi.br/revista/index.php/revista/article/view/767/pdf_121. Acesso em 18 abr. 2021.

MALVA, J. J. O. Neurociência: A Ciência do Cérebro. Reino Unido: The British Neuroscience Association, 2007.

MARTÍNEZ, A. M. O que pode fazer o psicólogo na escola?. Em aberto, v. 23, n. 83, 2010. Disponível em: https://repositorio.unb.br/bitstream/10482/6292/1/ARTIGO_QuePodeFazer.pdf. Acesso em: 18 abr. 2021.

MELO-JUNIOR, W.; MARTINUCCI, B.; JÚNIOR, L. A. L. MATHEUS, S. M. M. Neurobiologia da aprendizagem escolar. In: CONGRESSO NACIONAL DE FORMAÇÃO DE PROFESSORES, 2. CONGRESSO ESTADUAL PAULISTA SOBRE FORMAÇÃO DE EDUCADORES, 7. 2014, Águas de Lindoia, SP. Anais... Águas de Lindoia, SP, 2014. p. 4691-4700.

MAZER, S. M.; BELLO, A. C. D.; BAZON, M. R. Dificuldades de aprendizagem: revisão de literatura sobre os fatores de risco associados. Psicologia da educação, n. 28, p. 7-21, 2009. Disponível em: http://pepsic.bvsalud.org/pdf/psie/n28/v28a02.pdf. Acesso em: 18 abr. 2021.

MEDEIROS, V.; RODRIGUES, M. J.; CAVALCANTE, C. A formação e o perfil dos professores de Biologia na cidade de Jaguaribe (Ceará, Brasil) e professores de Biologia e Geologia na cidade de Bragança (Portugal). In: CONFERÊNCIA INTERNACIONAL SOCIEDADE PORTUGUESA DE CIÊNCIAS DA EDUCAÇÃO: A EDUCAÇÃO COMPARADA PARA ALÉM DOS NÚMEROS: CONTEXTOS LOCAIS, REALIDADES NACIONAIS E PROCESSOS TRANSNACIONAIS, 1. Atas... Sociedade Portuguesa de Ciências da Educação, Secção de Educação Comparada, 2017. p. 411-418.

MENDES, D. C.; CASTELANO, K. L.; MARTINS, L. M.; ANDRADE, C. C. F. A influência da autoestima no desempenho escolar. Educação em Debate, Fortaleza, ano 39, n. 73, jan./jun. 2017.

Disponível em:

http://www.repositorio.ufc.br/bitstream/riufc/28211/1/2017_art_dcmendesklcastelano.pdf. Acesso em: 18 abr. 2021.

OLIVEIRA-HAHN, T.; FERRARO, J. L. S. Aproximações entre as teorias de Wallon e Vygotsky no campo da educação: um olhar sobre a afetividade. Perspectiva, v. 36, n. 4, p. 1321-1337, out./dez., 2018. Disponível em: https://periodicos.ufsc.br/index.php/perspectiva/article/view/2175795X.2018v36n4p1321/pdf. Acesso em: 18 abr. 2021. 
PEIXOTO, M. R.; AGUIAR, E. C. O impacto do Tamanho da Classe na Percepção de Qualidade dos alunos de uma Instituição de Ensino Superior Privada Brasileira. Gestão \& Planejamento-G\&P, v. 19, p. 191-207, jan./dez., 2018. Disponível em: https://revistas.unifacs.br/index.php/rgb/article/view/4764/3452. Acesso em: 18 abr. 2021.

PEREIRA, É. F. Sono e sonolência diurna em adolescentes do Ensino Médio. 2011. 124 f. tese (Doutorado em Educação Física) Departamento de Educação Física, Setor de Ciências Biológicas da Universidade Federal do Paraná, 2011.

ROSA, M. G. O. S.; CASTRO, R. E. F. A mensuração da afetividade em sala de aula. Construção psicopedagógica, v. 25, n. 26, p. 24-33, 2017. Disponível em:

http://pepsic.bvsalud.org/pdf/cp/v25n26/04.pdf. Acesso em: 18 abr. 2021.

SAMPAIO, A. B. A. NASCIMENTO, H. R.; BRITO, G.; CÂMARA, C. M. F.; COUTINHO, E. M. C.; LIMA, J. M. C. Processos afetivos na relação professor e aluno: reflexões sobre a mediação do psicólogo escolar. Revista Expressão Católica, v. 6, n. 1, p. 54-62, jan./jun., 2018. Disponível em: http://publicacoesacademicas.unicatolicaquixada.edu.br/index.php/rec/article/view/2071/pdf. Acesso em: 18 abr. 2021.

SANTOS, M.; CARVALHO, T. S. S.; DOMINGUES, I. M. C. S. Escola da Terra: formação continuada para professores da educação do campo. Itinerarius Reflectionis, v. 15, n. 2, p. 01-20, 2019.

SILVA, R. F. As emoções e sentimentos na relação professor-aluno e sua importância para o processo de ensino e aprendizagem: contribuições da teoria de Henri Wallon, 2017. 162 f. Dissertação (Mestrado em Psicologia), Universidade Estadual Paulista (UNESP), Faculdade de Ciências e Letras, Assis, 2017. Disponível em:

https://repositorio.unesp.br/bitstream/handle/11449/150708/silva_rf_me_assis_int.pdf?sequence=6 \&isAllowed=y. Acesso em: 10 abr. 2021.

TASSONI, E. C. M.; SILVA-LEITE, S. A. Um estudo sobre emoções e sentimentos na aprendizagem escolar. Comunicações, v. 18, n. 2, p. 79-91, jul./dez., 2011. Disponível em:

https://www.metodista.br/revistas/revistas-unimep/index.php/comunicacoes/article/view/933/603. Acesso em: 18 abr. 2021.

TASSONI, E. C. M.; SILVA-LEITE, S. A. S. Afetividade e aprendizagem: a relação professoraluno. In: 23a Reunião Anual da ANPEd, 2000, Caxambu, MG. Anuário-2000 Psicologia: análise e crítica da prática educacional. Goiás: Gráfica e Editora Vieira, 2000.

TAVARES, M. R. A relação entre as emoções e os processos cognitivos na aprendizagem à luz do pensamento complexo. The ESPecialist, v. 35, n. 1, p. 28-41, 2014. Disponível em:

https://revistas.pucsp.br/index.php/esp/article/view/21307/15577, Acesso em: 18 abr. 2021.

VALE, L. E. L. R. VALE, E. L. R; REIMÃO, R. Sono e aprendizagem. Revista Psicopedagogia, v. 26, p.286-290, 2009. Disponível em:

<https://cdn.publisher.gn1.link/revistapsicopedagogia.com.br/pdf/v26n80a13.pdf.> Acesso em: 18 abr. 2021.

WALLON, H. Psicologia e Educação da Infância. Lisboa: Editorial Estampa, 1975.

Submissão: 01/03/2021

Aceito: 25/05/2021 